Available online at GSC Online Press Directory

GSC Biological and Pharmaceutical Sciences

e-ISSN: 2581-3250, CODEN (USA): GBPSC2

Journal homepage: https://www.gsconlinepress.com/journals/gscbps

(RESEARCH ARTICLE)

\title{
Formulation and in vitro characterization of tapentadol HCL as immediate release tablets
}

\author{
Suresh Kumar Paramasivam *, Priyanka Batlanki, Sindhu Vemula, Jagannath Patro Varanasi, Praveen \\ Kumar T and Yasmin Sulthana Syed
}

Department of Pharmaceutics, Browns College of Pharmacy, Khammam, Telangana, India.

Publication history: Received on 27 July 2018; revised on 21 August 2018; accepted on 29 August 2018

Article DOI: https://doi.org/10.30574/gscbps.2018.4.3.0072

\begin{abstract}
The aim of the present study is to develop and evaluate the immediate release tablet of tapentadol by direct compression method. The superdisintegrant explotab, solutab and polyplasdoneXL were used for immediate release of drug from tablet. The prepared tablets were evaluated for all pre-compression parameters and post-compression parameters. The drug-excipients interaction was investigated by FTIR. All formulation showed compliances with Pharmacopoeial standards. The study reveals that formulations prepared by direct compression F2 exhibits highest dissolution using explotab showed faster drug release $95.48 \%$ over the period of $45 \mathrm{~min}$ while disintegration time of the tablet was showed $12 \mathrm{sec}$ in comparison to other formulations of tapentadol.
\end{abstract}

Keywords: Immediate release; Explotab; Solutab; Polyplasdone XL

\section{Introduction}

An immediate release dosage form allows a manufacturer to extend market exclusivity while offering patients a convenient dosage form or dosage regimen. Immediate Release Tablets are those tablets which are designed to disintegrate and release their medication with no special rate controlling features such as special coatings and other techniques [1, 2], immediate releases and fast dispersing drug delivery system may offer a solution to these problems. Recently, immediate release tablets have started gaining popularity and acceptance as a drug delivery system, mainly because they are easy to administer, has quick onset of action is economical and lead to better patient compliance. They are also a tool for expanding markets, extending product life cycles and generating opportunities. [3, 4].

Immediate release tablets are those which disintegrate rapidly and get dissolved to release the medicaments. Immediate release may be provided by way of an appropriate pharmaceutically acceptable diluent or carrier, which diluent or carrier does not prolong to an appreciable extent, the rate of drug release and/or absorption. This term excludes formulations which are adapted to provide for "modified", "controlled", "sustained", "prolonged", "extended" or "delayed" release of drug [5, 6].

The immediate-release formulation of Tapentadol is indicated for the relief of moderate to severe acute pain. The longacting formulation serves as a continuous, around-the-clock analgesic that is indicated for the relief of moderate to severe chronic pain or neuropathic pain associated with diabetic peripheral neuropathy [7]. The main objective of this work was to investigate the possibility of obtaining a immediate release formulation of Tapentadol by using different polymer ratios. The various physicochemical characteristics and the in -vitro release rates from these study.

\footnotetext{
${ }^{*}$ Corresponding author

E-mail address: surae81@gmail.com
}

Copyright (C) 2018 Author(s) retain the copyright of this article. This article is published under the terms of the Creative Commons Attribution Liscense 4.0. 


\section{Material and methods}

\subsection{Materials}

Tapentadol powder was kindly provided by Aurobindo Pharmaceutical (Hyderabad). All other excipients and materials used during the experiment are LR grade or the best possible pharma grades available were used as supplied by the manufacturer.

\subsection{Pre formulation studies}

Pre formulation involves the application of biopharmaceutical principles to the physicochemical parameters of drug substance are characterized with the goal of designing optimum drug delivery system [8].

\subsection{Drug-excipients compatibility studies}

Drug excipients compatibility studies were carried out by mixing the drug with various excipients in different proportions (in 1:1 ratio were prepared to have maximum likelihood interaction between them) was placed in a vial, and closed with rubber stopper and sealed properly [9].

\subsection{Formulation of tapentadol immediate release tablet}

Drug and different concentrations for super Disintegrates and required ingredients were accurately weighed and passed through a 40-mesh screen to get uniform size particles and mixed in a glass mortar for 15 minutes. The obtained blend was lubricated with Magnesium stearate and glidant (Talc) was added and mixing was continued for further 5 minutes. The resultant mixture was directly compressed into tablets by using punch of rotary tablet compression machine. Compression force was kept constant for all formulations [10].

Table 1 Formulation of immediate release tablets

\begin{tabular}{llllllllll}
\hline Ingredients (mg) & F1 & F2 & F3 & F4 & F5 & F6 & F7 & F8 & F9 \\
\hline Tapentadol & 120 & 120 & 120 & 120 & 120 & 120 & 120 & 120 & 120 \\
Explotab & 40 & 80 & 120 & - & - & - & - & - & - \\
Solutab & - & - & - & 40 & 80 & 120 & - & - & - \\
Polyplasdone XL & - & - & - & - & - & - & 40 & 80 & 120 \\
Sodium stearylfumerate & 3 & 3 & 3 & 3 & 3 & 3 & 3 & 3 & 3 \\
Talc & 1 & 1 & 1 & 1 & 1 & 1 & 1 & 1 & 1 \\
Menthol & 1.5 & 1.5 & 1.5 & 1.5 & 1.5 & 1.5 & 1.5 & 1.5 & 1.5 \\
MCC & 134.5 & 94.5 & 54.5 & 134.5 & 94.5 & 54.5 & 134.5 & 594.5 & 94.5 \\
Total weight of tablets & 300 & 300 & 300 & 300 & 300 & 300 & 300 & 300 & 300 \\
\hline
\end{tabular}

\subsection{Quality control study of the prepared tablets}

The prepared tablets from each formulation were subjected to the tablets quality control tests as drug content, weight uniformity, tablets thickness, disintegration time, hardness and friability [11].

\subsubsection{Thickness}

The thickness of tablets was determined by using Digital micrometer. Ten individual tablets from each batch were used and the results averaged.

\subsubsection{Weight variation}

Twenty tablets randomly selected from each batch and individually. Weighed. The average weight and standard deviation three batches were calculated. It passes the test weight variation test if not more than two of the individual tablets weights deviate from the average weight by more than the allowed percentage deviation and more deviate by more than twice the percentage shown. It was calculated on an electronic weighing balance [12]. 


\subsubsection{Friability}

The friability values of the tablets were determined using a Roche-type friabilator. Accurately weighed six tablets were placed in Roche friabilitor and rotated at $25 \mathrm{rpm}$ for $4 \mathrm{~min}$ [13].

Percentage friability was calculated using the following equation.

$$
\text { Friability }=\frac{\mathrm{w}_{0}-\mathrm{w}}{\mathrm{w}_{0}} \times 100
$$

\subsubsection{Drug content}

The content of drug was carried out by five randomly selected tablets of each formulation. The five tablets were grinded in mortar to get powder, this powder was dissolved in $\mathrm{pH} 6.8$ phosphate buffer by sonication for 30 min and filtered through filter paper. The drug content was analyzed spectrophotometrically at $275 \mathrm{~nm}$ using UV spectrophotometer. Each measurement was carried out in triplicate and the average drug content was calculated.

\subsubsection{Disintegration test}

Six tablets were taken randomly from each batch and placed in USP disintegration apparatus baskets. Apparatus was run for 10 minutes and the basket was lift from the fluid, observe whether all of the tablets have disintegrated [14].

\subsubsection{Dissolution test of tapentadol HCL tablets}

Drug release from Tapentadol HCL tablets was determined by using dissolution test United States Pharmacopoeia (USP) 24 type II (paddle). The parameters used for performing the dissolution were $\mathrm{pH} 6.8$ phoshatebuffer as the dissolution medium of quantity $500 \mathrm{ml}$. the whole study is being carried out at a temperature of $37{ }^{\circ} \mathrm{C}$ and at speed of 50 rpm [15].

The $5 \mathrm{ml}$ aliquots of dissolution media were withdrawn each time at suitable time intervals $(5,10,15,20,25$ and 30 minutes.) and replaced with fresh medium. After withdrawing, samples were filtered and analyzed after appropriate dilution by UV Spectrophotometer. The concentration was calculated using standard calibration curve.

\section{Results and discussion}

\subsection{Characterization of precompression blend}

The precompression blend of tapentadol HCL were characterized with respect to angle of repose, bulk density, tapped density, Carr's index and Hausner's ratio. Angle of repose was less than $28^{\circ}$, Carr's index values were less than 11 for the precompression blend of all the batches indicating good to fair floability and compressibility. Hausner's ratio was less than 1.25 of all batches indicating good flow properties.

Table 2 Physical properties of precompression blend

\begin{tabular}{|c|c|c|c|c|c|}
\hline $\begin{array}{l}\text { Formulation } \\
\text { code }\end{array}$ & $\begin{array}{ll}\text { Angle } & \text { of } \\
\text { repose }(\theta)\end{array}$ & $\begin{array}{l}\text { Bulk density } \\
\left(\mathrm{gm} / \mathrm{cm}^{3}\right)\end{array}$ & $\begin{array}{l}\text { Tapped density } \\
\left(\mathrm{gm} / \mathrm{cm}^{3}\right)\end{array}$ & $\begin{array}{l}\text { Carr's index } \\
\text { (\%) }\end{array}$ & $\begin{array}{l}\text { Hausner's } \\
\text { ratio }\end{array}$ \\
\hline F1 & $25.10 \pm 1.18$ & $0.53 \pm 0.02$ & $0.59 \pm 0.03$ & $9.43 \pm 2.82$ & $1.11 \pm 0.15$ \\
\hline $\mathrm{F} 2$ & $25.43 \pm 1.37$ & $0.54 \pm 0.01$ & $0.60 \pm 0.01$ & $9.40 \pm 2.85$ & $1.10 \pm 0.04$ \\
\hline F3 & $25.41 \pm 2.12$ & $0.54 \pm 0.04$ & $0.58 \pm 0.04$ & $10.01 \pm 2.22$ & $1.07 \pm 0.07$ \\
\hline $\mathrm{F} 4$ & $26.40 \pm 0.53$ & $0.51 \pm 0.06$ & $0.61 \pm 0.07$ & $10.11 \pm 1.14$ & $1.19 \pm 0.03$ \\
\hline F5 & $27.12 \pm 0.83$ & $0.58 \pm 0.07$ & $0.63 \pm 0.09$ & $10.34 \pm 3.21$ & $1.08 \pm 0.01$ \\
\hline F6 & $25.31 \pm 0.91$ & $0.59 \pm 0.09$ & $0.64 \pm 0.01$ & $10.12 \pm 0.27$ & $1.08 \pm 0.03$ \\
\hline F7 & $26.11 \pm 1.07$ & $0.56 \pm 0.05$ & $0.63 \pm 0.02$ & $9.93 \pm 3.94$ & $1.12 \pm 0.05$ \\
\hline F8 & $26.15 \pm 0.62$ & $0.53 \pm 0.04$ & $0.58 \pm 0.03$ & $10.13 \pm 1.29$ & $1.09 \pm 0.08$ \\
\hline F9 & $26.10 \pm 0.83$ & $0.54 \pm 0.02$ & $0.61 \pm 0.08$ & $10.2 \pm 1.37$ & $1.12 \pm 0.09$ \\
\hline
\end{tabular}




\subsection{Drug-excipient compatibility studies by FTIR studies}

Tapentadol HCL was mixed with various proportions of excipients showed no colour change at the end of two months, providing no drug-excipient interactions.

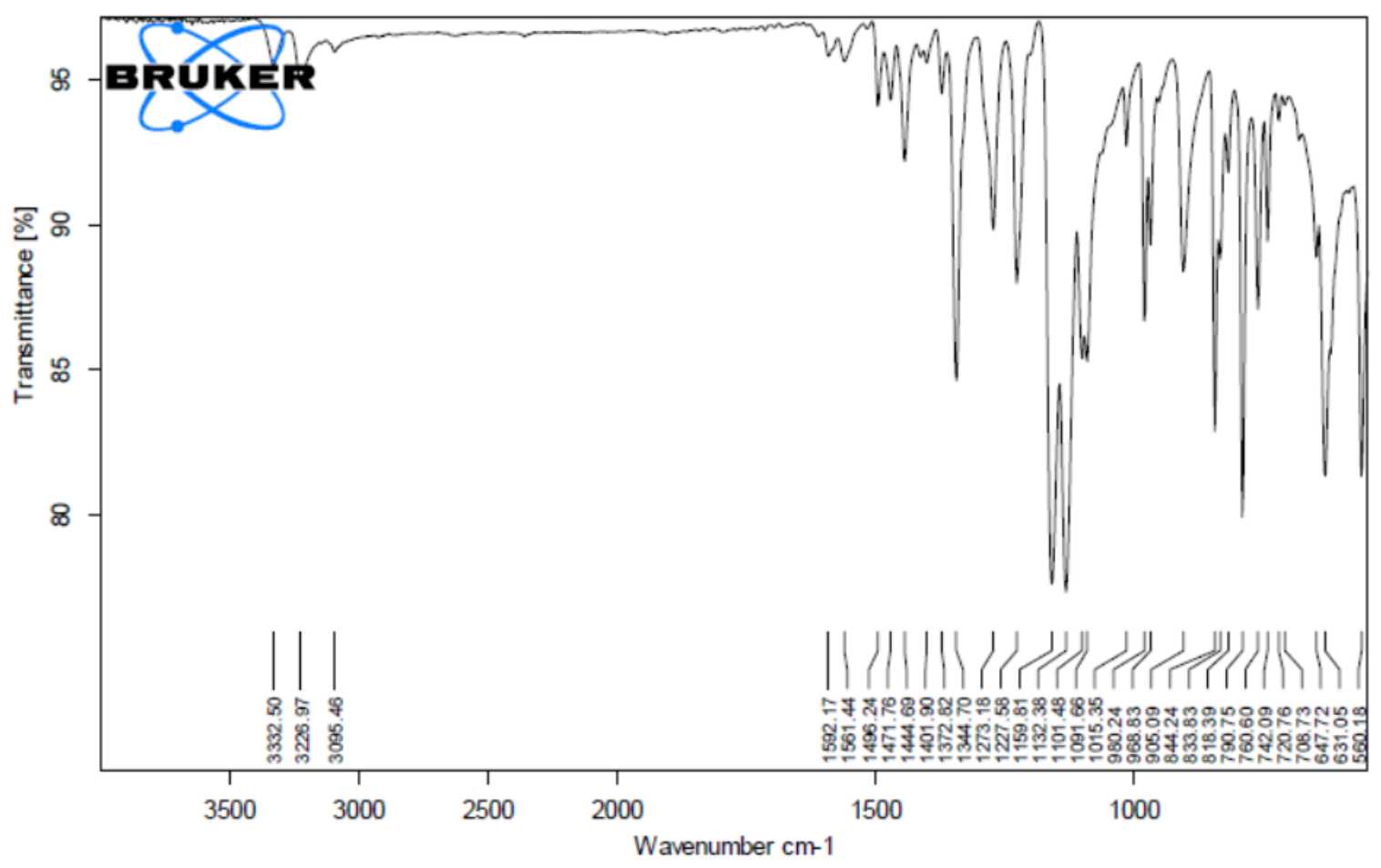

Figure 1 FTIR spectra of pure drug

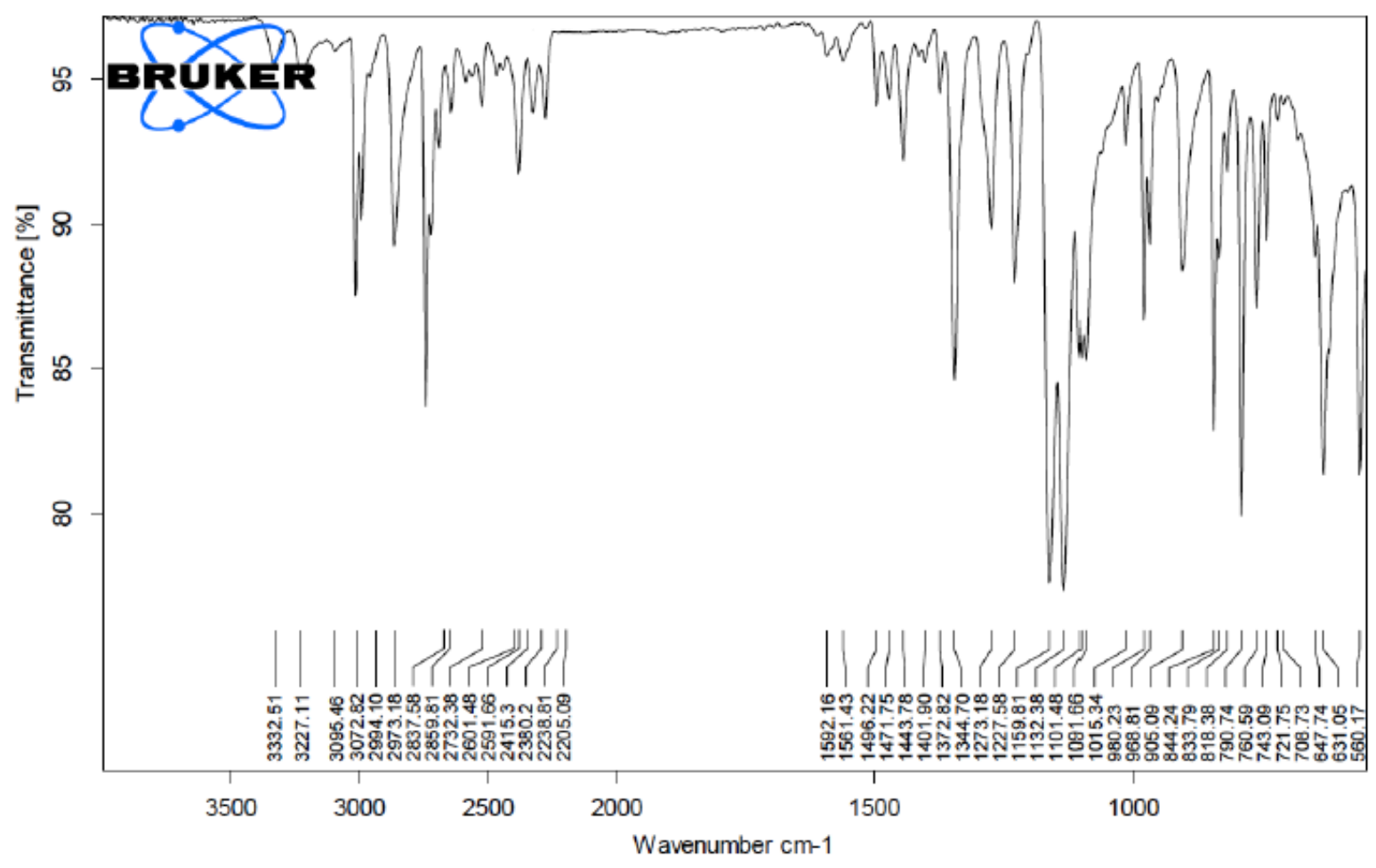

Figure 2 FTIR spectra of optimized formulation 


\subsection{Evaluation of tablets}

The results of the weight variation, hardness, thickness, friability, and drug content of tablets are given in table. All the tablets of different batches complied with the official requirement of weight variation as their weight variation passes the limit. The hardness of the tablets ranged from $4.6-5 \mathrm{~kg} / \mathrm{cm}^{2}$ and the friability values were $<$ than $0.561 \%$ indicating that the tablets were compact and hard. The thickness of the tablets ranged from $4.71-4.91 \mathrm{~cm}$. All the formulations satisfied the content of the drug as they contained $98-100 \%$ of Tapentadol HCL and good uniformity in drug content was observed. Thus all physical attributes of the prepared tablets were found to be practically within control limits.

Table 3 Physical evaluation of tapentadol HCL

\begin{tabular}{lllllll}
\hline $\begin{array}{l}\text { Formulation } \\
\text { code }\end{array}$ & $\begin{array}{l}\text { Average } \\
\text { Weight } \\
\text { (mg) }\end{array}$ & $\begin{array}{l}\text { Thickness } \\
\text { (cm) }\end{array}$ & $\begin{array}{l}\text { Hardness } \\
\text { (Kg/cm } \mathbf{~})\end{array}$ & $\begin{array}{l}\text { Friability } \\
\text { (\%) }\end{array}$ & $\begin{array}{l}\text { Content } \\
\text { uniformity (\%) }\end{array}$ & $\begin{array}{l}\text { In Vitro } \\
\text { Disintegration time } \\
\text { (Seconds) }\end{array}$ \\
\hline F1 & $300.4 \pm 0.2$ & $4.76 \pm 0.64$ & $2.5 \pm 0.5$ & $0.420 \pm 0.02$ & 99.12 & 19 \\
F2 & $299.9 \pm 0.1$ & $4.74 \pm 0.57$ & $2.2 \pm 0.3$ & $0.341 \pm 0.01$ & 99.03 & 12 \\
F3 & $301.5 \pm 0.5$ & $4.71 \pm 0.80$ & $2.1 \pm 0.1$ & $0.363 \pm 0.05$ & 99.98 & 24 \\
F4 & $299.7 \pm 0.3$ & $4.80 \pm 0.68$ & $2.1 \pm 0.8$ & $0.561 \pm 0.07$ & 99.87 & 26 \\
F5 & $300.9 \pm 0.1$ & $4.81 \pm 0.46$ & $2.0 \pm 0.2$ & $0.482 \pm 0.09$ & 99.63 & 17 \\
F6 & $300.2 \pm 0.8$ & $4.74 \pm 0.57$ & $2.2 \pm 0.7$ & $0.513 \pm 0.05$ & 99.41 & 15 \\
F7 & $299.1 \pm 0.9$ & $4.76 \pm 1.06$ & $2.2 \pm 0.1$ & $0.412 \pm 0.04$ & 97.94 & 23 \\
F8 & $301.4 \pm 0.5$ & $4.71 \pm 0.64$ & $2.3 \pm 0.2$ & $0.432 \pm 0.03$ & 96.16 & 16 \\
F9 & $298.9 \pm 0.2$ & $4.73 \pm 1.15$ & $2.5 \pm 0.1$ & $0.512 \pm 0.01$ & 98.67 & 14 \\
\hline
\end{tabular}

\subsection{In vitro release studies}

The drug release rate from tablets was studied using the USP type II dissolution test apparatus. The dissolution medium was $500 \mathrm{ml}$ of $\mathrm{pH} 6.8$ phosphate buffer at $50 \mathrm{rpm}$ at a temperature of $37 \pm 0.5{ }^{\circ} \mathrm{C}$. Samples of $5 \mathrm{ml}$ were collected at different time intervals up to $45 \mathrm{~min}$ and has analyzed after appropriate dilution by using UV spectrophotometer at 275 nm.

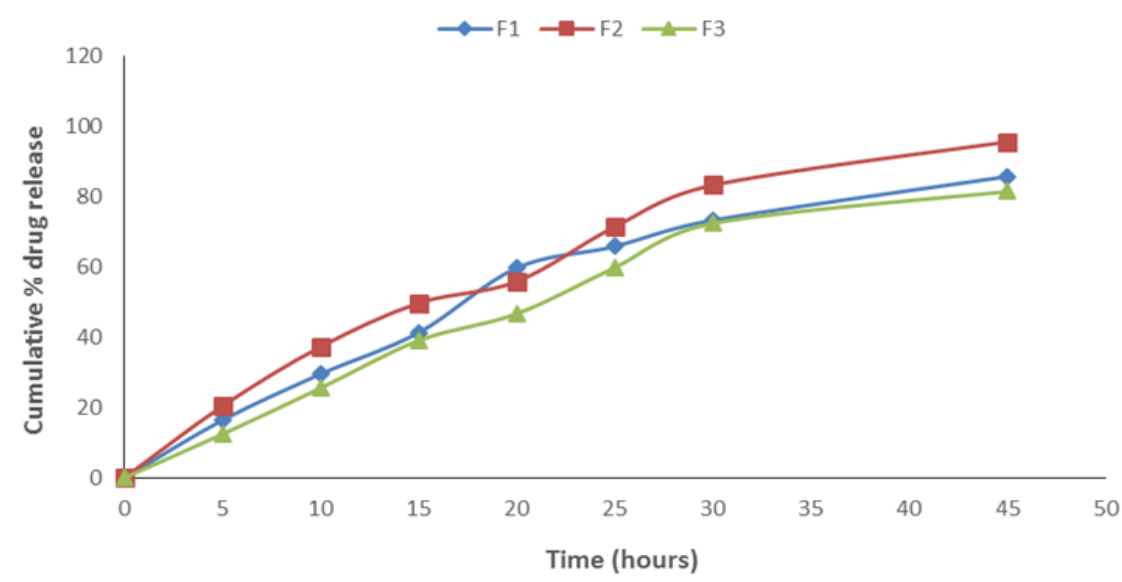

Figure 3 In vitro dissolution data for formulation F1-F3

Among all the formulations F2 formulation containing drug and explotab showed good result that is $95.48 \%$ in 45 minutes, at the concentration of $80 \mathrm{mg}$. Hence from all the formulations it is evident that F2 formulation is the better formulation. 


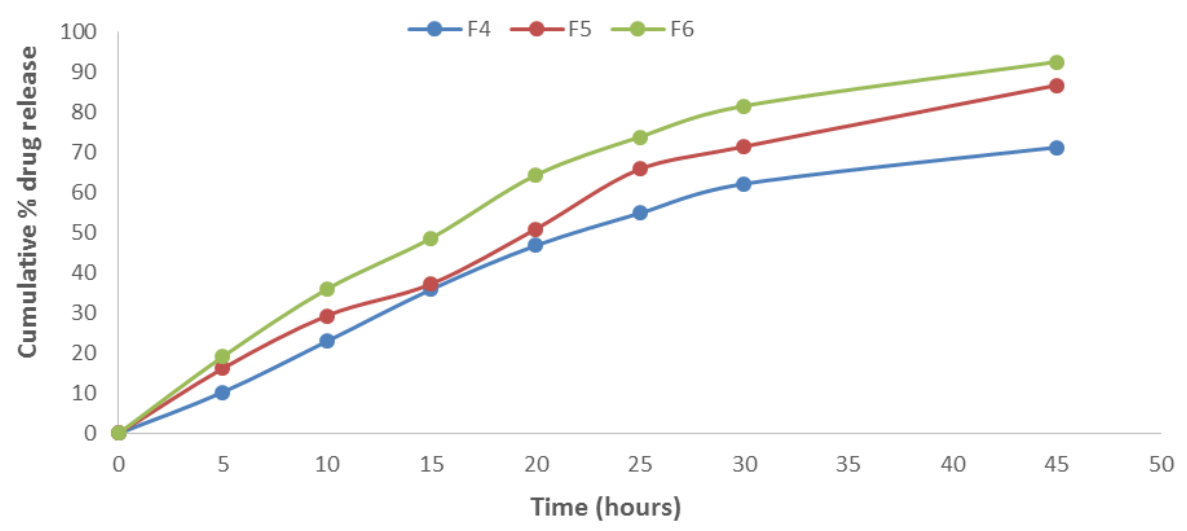

Figure 4 In vitro dissolution data for formulations F4-F6

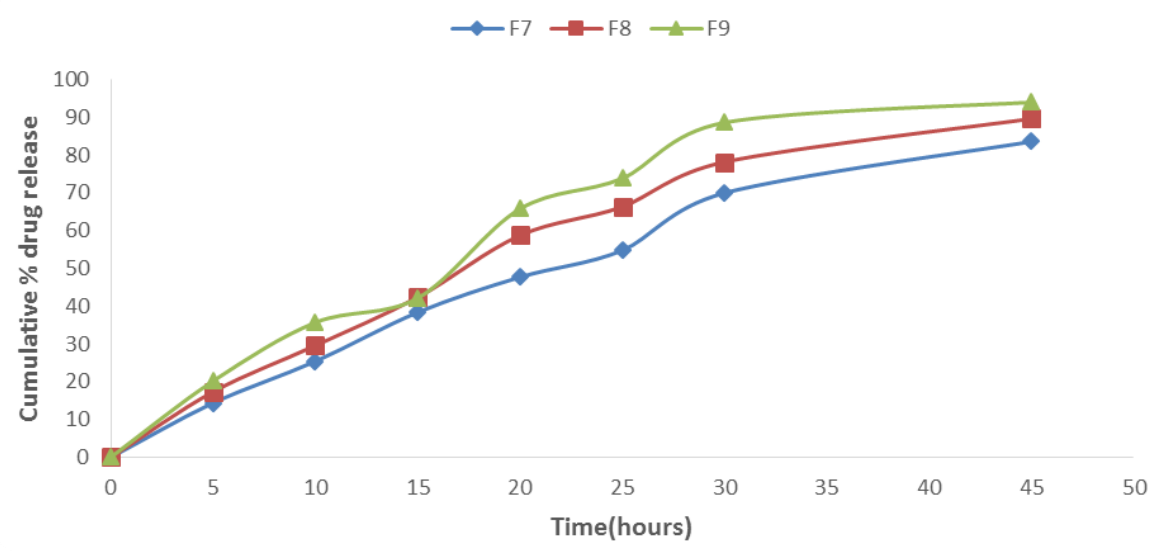

Figure 5 In vitro dissolution data for formulations F7-F9

\section{Conclusion}

The formulation of immediate release tablets of tapentadol hydrochloride were prepared by direct compression method by using different ratios of superdisintegrant explotab, solutab and polyplasdone XL. Among all the formulations, the formulation F2 exhibits highest dissolution using explotab, faster drug release $95.48 \%$ over the period of 45 min while disintegration time of the tablet was showed $12 \mathrm{sec}$. Therefore the prepared formulation of tapentadol hydrochloride containing explotab is best formulation and could be used for industrial application.

\section{Compliance with ethical standards}

\section{Acknowledgments}

With deep gratitude, I would like to thank the management, Browns College of Pharmacy for providing all the necessary facilities in the college campus to carry out research work.

\section{Disclosure of conflict of interest}

The author declare that there is no conflict of interest. 


\section{References}

[1] Jishan Ali Ahmed. (2015). A review on immediate release tablet dosage form. Human Journals, 2(3), 1-17.

[2] Bindu T, Kumar P, Rao JR, Rao PN and Manasa M. (2014). Formulation and development of Sorafenib tosylate immediate release tablet. International Journal of Innovative Pharmaceutical Sciences and Research, 2(7), 13861401.

[3] Bokshi B and Malakar A. (2012). Formulation and evaluation of Allylestrenol immediate release tablets. IJPSR, 3(6), 1679-83.

[4] Jadhav SB, Mali AD, Rajeghadage SH and Bathe RS. (2014). Formulation and evaluation of immediate release tablets of Imipramine hydrochloride. Int. J. Biomed. Adv. Res, 5(11), 559-565.

[5] Neha D, Kamini KM, Neeraj P, Manmohan S, Kamal V and Neeraj SN. (2017). Immediate release tablets: A review. World Journal of Pharmacy and Pharmaceutical Sciences, 6(4), 595-611.

[6] Jagdale SC, Patil SA and Kuchekar BS. (2012). Design, development and evaluation of floating tablets of tapentadol hydrochloride using chitosan. Asian Journal of Pharmaceutical and Clinical Research, 5(4), 163-168.

[7] Vadivelu N, Timchenko A, Huang Y and Sinatra R. (2011). Tapentadol extended-release for treatment of chronic pain: a review. Journal of pain research, 4, 211.

[8] Vilegave, K, Vidyasagar, G and Chandankar P. (2013). Preformulation studies of pharmaceutical new drug molecule and products: An Overview. Am. J. Pharm Health Res, 1(3), 1-20.

[9] Vageesh NM, Sura RS, Rafian D and Govindamma U. (2017). Preparation and In vitro charactersation of fast disintigrating tablets of cimetidine. Innovat International Journal of Medical and Pharmaceutical Sciences, 2(4), 1-6.

[10] Reddy DV and Rao DAS. (2014). Formulation and evaluation of extended release tablets of Tapentadol hydrochloride using hydrophilic-hydrophobic polymer combinations. J Pharma Res, 8(10), 1368-1374.

[11] Teklu, L, Adugna E and Ashenef A. (2014). Quality evaluation of paracetamol tablets obtained from the common shops (kiosks) in Addis Ababa, Ethiopia. International journal of pharmaceutical sciences and research, 5(8), 3502.

[12] Maheswarappa MK and Desai PD. (2014). Design and in-vitro evaluation of mouth dissolving tablets of olanzapine. Asian Journal of Pharmaceutics, 5(2).

[13] Mohammad S, Mohammad S, Bijja S and Ashraf B. (2014). Evaluation of tablets by friability apparatus. International Journal of Research in Pharmacy and Chemistry, 4(4), 837-840.

[14] Aher VS, Bhairav BA and Saudagar RB. (2016). Formulation evaluation and comparative study of zolmitriptan mouth dissolving tablet. Asian Journal of Pharmacy and Technology, 6(4), 207-216.

[15] Son YJ and McConville JT. (2009). Development of a standardized dissolution test method for inhaled pharmaceutical formulations. International Journal of Pharmaceutics, 382(1-2), 15-22.

\section{How to cite this article}

Suresh Kumar P, Priyanka B, Sindhu V, Jagannath Patro V, Praveen Kumar T and Yasmin Sulthana S. (2018). Formulation and in vitro characterization of tapentadol HCL as immediate release tablets. GSC Biological and Pharmaceutical Sciences, 4(3), 42-48. 